\title{
Exploring factors associated with self-treatment among different elder subgroups in rural China: a cross-sectional study
}

Wanchun Xu

School of Medicine and Health Management, Huazhong University of Science and Technology

Zhong Li

School of Medicine and Health Management, Huazhong University of Science and Technology

Zijing Pan

School of Medicine and Health Management, Huazhong University of Science and Technology

Ruibo He

School of Medicine and Health Management, Huazhong University of Science and Technology

Liang Zhang ( $\sim$ zhanglianghust@126.com )

Huazhong University of Science and Technology https://orcid.org/0000-0002-7870-5460

Research article

Keywords: self-treatment, the elderly, rural China, family practice, empty nest

Posted Date: July 3rd, 2019

DOI: https://doi.org/10.21203/rs.2.10872/v1

License: @ (i) This work is licensed under a Creative Commons Attribution 4.0 International License. Read Full License 


\section{Abstract}

Background Self-treatment is a common and widespread behaviour, of which the risks are multiplied in old age. However, the determinants of self-treatment among elders in the current rural China remain unclear. This study aims to explore the determinants of self-treatment among elders in rural China, focusing on context-specific and multi-dimensional factors. Methods Based on a multi-stage stratified random sampling method, a cross-sectional household survey was conducted among 30 villages in Sinan County, Guizhou Province in western China. Data were collected through a self-administered questionnaire on the healthcare needs of residents. The analysis was restricted to elders who reported illness within the last 2 weeks, and the final sample size was 338 (individuals). Pearson's chi-squared test and binary logistic regression analysis were performed among the whole sample group and four subgroups. Results Approximately $25.94 \%$ of the 1303 elders reported illness within the last 2 weeks, of whom $34.4 \%$ indicated self-treatment. The variables independently associated with a greater probability of self-treatment in the whole sample group were better health status, no recent alcohol consumption and no utilisation of family practice services; the same predictors were found in the subgroup of elders with chronic diseases. No significant predictors were found in the subgroup of elders without chronic diseases. Empty-nest elders with higher affinity to traditional Chinese medicine (TCM) and drinking alcohol recently were less likely to self-treat. Non-empty-nest elders who were no less than 75 years old and at better health status were more likely to self-treat. Conclusion Better health status, no recent alcohol consumption and no utilisation of family practice are associated with self-treatment among rural elders. Advanced age and self-care habits in TCM also play roles in some subgroups. Deeper understanding of the self-treatment behaviour among rural elders may provide insights for developing improvement strategies of the family practice system in China.

\section{Background}

Progressive aging has raised a great challenge to the healthcare system in many countries. As the WHO advocated, the fragmented healthcare systems need to be transformed to provide integrated healthcare services to respond to the needs of the elderly. Some developed countries, such as the UK, Australia and Canada, have established relatively complete healthcare delivery systems for the elderly [1]. However, the availability of affordable and convenient medical care to elders in low and middle income countries (LMICs) is still far from being satisfactory [2]. Costly medical expense, inconvenience to medical visit, distrust on the healthcare system and other social changes lead to the non-use of health services or self-treatment behaviour of the elderly [3-5]. Due to the increasing drug availability and the permissive regulation of drug retailing, the latter choice is more common in LMICs [6].

Self-treatment is highly prevalent among the elderly in some countries. A systematic review revealed that the prevalence of self-medication among elders varies from $20 \%$ to $60 \%$ in most studies [7]. The data of the China National Health Survey (CNHS) in 2013 suggested that the prevalence of self-treatment among the elderly is $44.2 \%$, with a slight difference between urban (43.1\%) and rural (45.8\%) areas [6]. Although self-treatment can increase the individuals' availability of medical help and reduce the pressure on the healthcare system, several risks are involved in self-treatment, such as incorrect self-diagnosis, delays in seeking for professional help and adverse drug reactions (ADR) due to the inappropriate use of medicine [8, 9]. Some previous studies have shown that elders are at higher risk for illness than other age groups; thus, elders are also prone to greater consumption of drugs and higher risk of inappropriate drug use [10], which may result in serious ADRs due to age-related changes in the pharmacokinetics and pharmacodynamics of drugs [11]. Therefore, in-depth studies on the self-treatment issue of elders must be conducted to deepen the understandings of their health-seeking pattern and thus shed lights on the improvement of the primary care system in rural China.

An official or agreed definition of 'self-treatment' is still lacking worldwide. The CNHS defines 'self-treatment' as 'taking some drugs and/or other remedies, or having a massage and/or physiotherapy rather than visiting a physician when experiencing symptoms or complaints during the two-week period preceding the survey' [12]. In a previous study of self-treatment in central China, self-treatment refers to 'the scenario where a person uses unprescribed drugs or other approaches to cope with illness conditions' [13]. Referring to the previous study, self-treatment is defined in this article as 'taking unprescribed drugs and/or other approaches to cope with the symptoms or complaints during the two-week period preceding the survey', including self-treating with self-diagnosis and with the previous diagnosis of professionals. The concept of self-treatment differs from those of self-medicine and self-care. According to the WHO, selfmedicine only refers to the use of medicine by individuals to treat self-recognised illness or symptoms, whereas self-care is a broader concept that refers to the practices of individuals to maintain health and prevent or deal with illness, encompassing hygiene, nutrition, lifestyle, environmental factors, socioeconomic factors and self-medication [14].

Previous studies have examined the potential determinants of self-medication and self-treatment behaviour among the elderly. Female sex, visits to pharmacists, depression, functional dependency, recent hospitalisation, oral pain and restriction of physical inactivity are positively associated with selfmedication, whereas medical appointments, married status, use of health services, satisfaction with living arrangement, living in institutional settings and private health plans are negatively related to the choice of self-medication [7]. Long-term illness is broadly proven to be associated with the higher possibility to self-medication [15] or self-treatment [12]. However, the factors examined in studies with Chinese settings mostly included the socio-demographic characteristics and health status of individuals, and the roles of the factors of the health-care delivery system and the social changes [5] were rarely given attention. This knowledge gap may result in an incomprehensive understanding of the mechanisms underlying the self-treatment behaviour of the elderly in China. The decision to self-treat involves an interaction between internal dynamic and external strengthening mechanisms, including individual, household, accessibility and medical insurance system factors [12], which need to be further explored and verified in the specific and typical context of rural China.

According to the literature review, several factors in the setting of rural China may contribute to the better understanding of the knowledge gaps mentioned above, which have been scarcely discussed in previous studies. Firstly, the condition of the family practice system may influence the rural elders' healthseeking behaviour, including resorting to self-treatment. The family practice contract service has been implemented in China in the new round of the healthcare reform since 2009 , aiming to build a closer relationship between the residents and family practice physicians, which would help doctors improve the efficacy and comprehensiveness of primary care services [16]. However, the effect of the family practice on the residents' health-seeking behaviour in China has not been fully explored yet. Secondly, as for the social changes, China is experiencing rapid aging and urbanisation, and the number of empty-nest

Page 2/11 
elders who are living away from their children is increasing in rural areas. The impact of family caregivers on the care of the elderly as well as the elders' medical decision-making has been well documented [17-20]. A study on the empty-nest elderly in China indicated that empty-nest seniors have a higher nonuse rate of healthcare services than non-empty-nest ones [21]. The empty-nest effect on the elders' self-treatment remains unknown. Thirdly, the role of traditional Chinese Medicine (TCM) is worthy of attention. TCM is prevalent in almost all ethnic Chinese societies, and the TCM theory is often used to guide self-care practices in the daily life of Chinese people [22]. However, not only the research published in English but also the papers in Chinese present a serious shortage of discussion on the self-treatment issue from the perspective of TCM [23].

In this study, we explored the factors associated with self-treatment among the elderly using the results of a household survey conducted in a poor county in western rural China. The variables related to the knowledge gaps mentioned above were considered in the study design, which distinguishes this study from previous ones. Considering that the long-term illness [24, 25] and condition of the caregivers [19] may influence the elders' health-seeking pattern and decisionmaking on the self-treatment, we conducted the analysis separately in the whole sample group and four subgroups (i.e. elders with chronic diseases, elders without chronic diseases, empty-nest elders and non-empty-nest elders). A comprehensive understanding of the self-treatment issue among the different population groups is crucial to discovering not only the potential vulnerable groups who may be at higher risk of inequality to health service access [21], but also the service gaps [12] in the present primary care system. These findings will be constructive for the improvement of the healthcare delivery system for the elderly.

\section{Methods}

\section{Study design and population}

This study was based on the data from a national survey to assess the residents' healthcare needs, which is a part of a joint multi-agent study on the issue of capacity-building of the primary care system in China. The national household survey of the residents' healthcare need assessment was conducted in four counties/districts across China, including the two districts in urban area (Futian in eastern China, Xiling in central China) and two counties in rural area (Dangyang in middle China, Sinan in western China). The data collected in Sinan, an impoverished county in western China, were analysed in this article. The household survey in Sinan was conducted in July, 2018. A multi-stage stratified random sample was drawn to conduct one-to-one interviews. A sample of 3983 individuals in 1355 households in 30 villages was selected in Sinan. Our analysis was restricted to the population of the elderly (no less than 60 years old) who reported the presence of illness during the two-week period before they were interviewed. The final sample size was 338 (individuals).

This study was approved by the Ethics Committee of Tongji Medical Collage, Huazhong University of Science and Technology (IORG No: IORG0003571).

\section{Materials and variables}

Data were collected through household-individual combined questionnaires, including basic information of families, individual demographic background, health condition, health habits, healthcare seeking behaviour and utilisation of family practice. To identify individuals' self-treatment behaviour, we used the following questions from the questionnaires: 'How did you treat your illness in the past 2 weeks?' The response options were: 1) self-treatment (self-medicine or other approaches); 2) outpatient visit; 3) hospitalisation; 4) no treatment; 5) under treatment with doctors' instruction. The first choice was considered as 'self-treatment'. Thus, a new dependent variable was created to determine if a person practises self-treatment (self-treatment versus non-self-treatment).

We used the factors of socio-demographic status, health status and health habits to describe the individual characteristics. All socio-demographic variables were dichotomised, including (1) gender (male and female), (2) age (60-74 or $\geq 75$ ), (3) in poverty (yes or no), (4) illiteracy (yes or no) and (5) the condition of family caregivers (empty-nest or non-empty-nest). The identification system of the poor families is well-developed and strict in the welfare system in China [26]. Thus, we considered those recognised as 'poor family' by the officials under poverty population. Empty-nest elders refer to those who live alone (emptynest singles) or with a spouse (empty-nest couples) [21]. The EQ-5D-3L (three-level EuroQol five-dimensions) instrument was applied to access the respondents' health status. Time trade-off (TTO) values were calculated to quantify the subjects' health status according to the model for Chinese people [27] The TTO values ranged from -0.149 to 1 , and higher values represent better health status. Suffering from chronic diseases or multiple morbidities was also used as a variable to describe the elders' health condition. Variables of health habits include (1) self-care in TCM (yes or no) and (2) recent alcohol consumption (yes or no). Self-care in TCM includes massaging, emotional therapy, dietary supplement usage, traditional sports therapy and other supplementary approaches to remain healthy in daily life as the philosophy of TCM suggests [28]. Recent alcohol consumption refers to drinking alcohol at least once a week in the previous 6 months and more. Variables of the healthcare delivery system include (1) distance to the nearest medical institution ( $<1$, $2-3,>3 \mathrm{~km}$ ) and (2) utilisation of family practice services (yes or no). The utilisation of family practice services refers to the fact that the elders who had signed the contracts with the family doctors in the local primary care system have used one or more services in the contracts.

Other information, such as the self-treated diseases and the untreated rates, were also collected in this study, which will be given a descriptive analysis in this article.

\section{Statistical analysis}

Rates of self-treatment were calculated for each of the classified variables in the whole sample group and four subgroups. Statistical analysis was carried out using the Pearson's Chi-square test. Logistic regression analysis was conducted to estimate the independent effect of each of these variables on self-

treatment, and the $\mathrm{p}$-value, adjusted odds ratios and $95 \%$ confidence interval $(95 \% \mathrm{Cl})$ were reported. Five regression models were generated and analysed, one for the whole sample group and four for each of the elder subgroups. Data were analysed using Stata version 14.0. Statistical significance was set at $P<0.05$.

Page $3 / 11$ 


\section{Results}

Approximately $25.9 \%$ of the 1303 elders reported the presence of illness within the past 2 weeks before the investigation, of whom $34.4 \%$ reported selftreatment behaviour. In addition, the rate of untreated cases was $5 \%$. The most common self-treated illnesses included cold, hypertension, intervertebral disk disease and unknown illness (symptoms or discomfort of which the diagnosis or reasons remain unknown), of which the rates of self-treatment were $41.6 \%$, $24.0 \%, 27.9 \%$ and $55.0 \%$, respectively.

\section{Factors associated with self-treatment}

\section{Bivariate analysis}

The results of the bivariate analysis are presented in Table 1. In the whole sample group, an association was found between self-treatment and most of the variables. The female elders were more likely to self-treat their illness ( $41.5 \%$ of females; $30.0 \%$ of males; $p=0.029)$. The population groups of lower proportion of self-treatment included elders in poverty $(27.2 \%$ vs. $39.7 \%$; $p=0.028)$, elders with chronic disease $(32.7 \%$ vs. $45.5 \%$; $p=0.032)$ or multiple morbidities $(24.7 \%$ vs. $39.4 \%$; $p=0.018)$, elders with recent alcohol consumption ( $19.7 \%$ vs. $39.7 \%$; $=0.002)$ and elders who utilise family practice services $(30.4 \%$ vs. $41.4 \%$; $\mathrm{p}=0.037)$.

However, when the data were divided into different subgroups, the variables with significant differences in rates of self-treatment varied between groups. No significant determinants were observed in the subgroup of the elders without chronic diseases. As for the elders with chronic diseases, the proportion of people who self-treated was lower in those who lived in a poor family $(23.8 \%$ vs. $36.5 \%$; $p=0.045)$, liked self-care in TCM $(28.4 \%$ vs. $41.8 \%$; $p=0.036)$, consumed alcohol recently $(18.2 \%$ vs. $36.5 \%$; $p=0.011)$ or utilised family practice services $(26.8 \%$ vs. $38.7 \%$; $p=0.047)$. In the subgroup of non-empty-nest elders, those who were no less 75 years old were more likely to self-treat than those of $60-74$ years old $(57.1 \% \mathrm{vs.} 31.9 \%$, $\mathrm{p}=0.006)$. The non-empty-nest elders who consumed alcohol recently reported a lower rate of self-treatment than their counterpart $(22.2 \%$ vs. $40.1 \%$, $p=0.046)$. In the subgroup of empty-nest elders, the proportion of elders who self-treated was lower in those with chronic diseases than their counterpart ( $29.5 \%$ vs. $48.9 \%$; $p=0.021)$. Those empty-nest-elders with the habits of self-care in TCM $(29.1 \%$ vs. $46.3 \%$; $p=0.032)$ or drinking alcohol recently $(17.1 \%$ vs. $39.2 \%$; $p=0.016)$ were also less likely to self-treat.

\section{Logistic regression}

Eleven study variables, including the TTO values of the EQ-5D-3L instrument, were introduced into the logistic models (Table 2). Five regression models were generated according to the subgroup categories, whereas the model for the elders without chronic disease failed with no significant predictors ( $P=0.763$ ).

In the model for the whole sample, the variables which were independently and significantly associated with a high probability of self-treatment were high TTO value (OR 6.75, 95\% Cl 1.93-23.60), whereas recent alcohol consumption (OR $0.42,95 \% \mathrm{Cl} 0.21-0.83$ ) and utilisation of family practice services (OR 0.59 , $95 \% \mathrm{Cl} 0.36-0.96)$ predicted a low probability of self-treatment.

However, when analysed in different subgroups, the significant predictors and their weight were somewhat different (Table 2). In the subgroup with chronic diseases, the variables independently and significantly associated with high risks of self-treatment were TTO values (OR 13.56, 95\% Cl 2.81-65.39), whereas recent alcohol consumption ( $\mathrm{OR} 0.41 ; 95 \% \mathrm{Cl} 0.18-0.91$ ) and utilisation of family practice (OR $0.49,95 \% \mathrm{Cl} 0.27-0.89$ ) were associated with lower rates of self-treatment. No significant variables were independently associated with self-treatment in the subgroup of the elders without chronic disease ( $P=0.763)$. As for the subgroup of empty-nest elders, the variables that were independently and significantly associated with a low probability of self-treatment were the health habits of self-care in TCM approaches (OR, $0.39 ; 95 \% \mathrm{Cl}, 0.18-0.86)$ and recent alcohol consumption (OR, 0.28; 95\% Cl, 0.10-0.82). In the group of nonempty-nest elders, the elders who were no less than 75 years old (OR 3.10; $95 \% \mathrm{Cl} 1.32-7.20)$, as well as those in better health status-higher TTO values (OR 9.20; $95 \% \mathrm{Cl} 1.73-48.75)$, were more likely to self-treat their illness than their counterpart.

\section{Discussion}

\section{Main results}

The present study aimed to explore the determinants associated with self-treatment behaviour, focusing on multi-dimensional factors in the rural China context. We found that $34.4 \%$ of the elders with illness in the previous 2 weeks practised self-treatment. According to the result of logistic regression, selftreatment was strongly associated with better health status, no recent alcohol consumption and no utilisation of family practice in the whole sample group, which is the same in the subgroup of elders with chronic disease. However, no significant predictors were found associated with the self-treatment of elders without chronic diseases. From the perspective of family caregiver, we found that the empty-nest elders who liked self-care in TCM and consumed alcohol recently were less likely to self-treat than their counterpart. As for the non-empty nest group, the elders who were no less than 75 years old and at better health status were more likely to self-treat than their counterpart.

\section{Discussion of the main results}

\section{Prevalence of self-treatment}


This study showed that $34.4 \%$ of the subjects practised self-treatment. According to the 2013 report of CNHS, the prevalence of self-treatment was $47.2 \%$ among the elders in western rural China [6]. Another study conducted in Shanxi, a province in northwestern China, indicated that $79.4 \%$ of the middle-aged and elderly people resorted to self-treatment 12 months before the survey [13]. Most previous studies focused on the behaviour of self-medication and found that the rates of self-medication among the elderly range from $20 \%$ to $60 \%$ [7]. The difference in methodology, especially the definition of self-treatment and selfmedication, can account for the deviation in values. However, the proportion of untreated elders is $4.5 \%$, which is slightly higher than the result of CNHS (1.7\%, western rural China, 2013) [6]. Thus, considering the launching of the anti-poverty program for the sick poor people in China in recent years [29], we can infer that the decrease in self-treatment is due to the improved access to health care for the people in poor areas [30].

\section{Determinants of general population}

The decision of self-treatment involves an interaction between internal dynamic and external-strengthening mechanisms [12]. However, no socio-demographic factors were found significantly related to the elders' self-treatment, which is somewhat different from the previous results. The evidence from the CNHS in 2013 showed that the financial difficulties and inconvenience of consulting doctors are the main reasons for not seeking professional medical care for perceived non-severe illness [6]. Using the CNHS data in 1993, 1998, 2003 and 2008, Li et al. found that economic and individual factors, as well as accessibility to drugs, are significantly associated with self-treatment [12]. In addition, lower education [13], age and income [31] are found to be associated with self-treatment or self-medication among elders. A study based on the data from the China health and retirement longitudinal study reported that elders in middle income group are more likely to self-treat with over-the-counter (OTC) drugs than those in the lowest and highest income groups [31]. The insignificance of the socio-demographic factors suggests the pervasiveness of self-treatment among the rural elders in China and implied that the mechanism may relate more to the health behaviour in certain health condition.

The utilisation of family practice services is strongly associated with the lower possibility of self-treatment among the rural elders in the study. A crosssectional study in Spain indicated that visits to the family doctor or other specialists in the last 4 weeks are negatively related to self-treatment, especially in the age group of $45-74$ years [32]. An evidence in China indicated that residents who availed of family practice services perceive higher quality of primary care, including the aspect of first contact-access, continuity, comprehensiveness and coordination [16]. The utilisation of family practice may facilitate rural elders to the necessary medical services and reduce their resorting to self-treatment.

Better health status is also related to the self-treatment behaviour in this study. Some studies indicated that the prevalence of self-medication is higher among adults with poor self-rated physical and mental health than among others [33], which is different from the result in our study. One of the possible explanations in the rural China context is that the people in remote rural areas are less likely to seek professional medical services if the illness or injury is not severe because of the poor access to medical services in rural areas and the villagers' affordability of medical expenditure [34]. Thus, rural elders might resort to selftreatment when in a relatively stable health condition.

The negative relation between recent alcohol consumption and self-treatment also contradicted the results of previous studies at home and abroad. The data of the CNHS in 2008 reported a slightly higher proportion of self-treatment among those with drinking habits [12]. The middle-aged and elderly (45-74 years) with recent alcohol consumption in Spain are likely to resort to self-medication [32]. An empirical study in Finland showed that $19.2 \%$ of elders aged over 75 years old use alcohol as self-medication to cope with the heart and vascular disorders, sleep disorders, mental problems and other illnesses [35]. Some studies in alcohol consumption behaviour attributed the difference in drinking patterns to cultural aspects [36], which implies that there may be some confounding factors related to the subjects' cultural background because our study was conducted in a remote multi-ethnic county. Over 20 minority ethnic groups are living in the county of Sinan. Some of the minority ethnic groups living in this county have the canon of abstinence from alcohol [37], such as the Hui people, a branch of Muslim in China. A study in America illustrated found that American Muslims interpret their illness as part of God's will, which serves as a barrier for them in seeking medical care [38]. In addition, Islam provides an ethico-legal framework for making clinical decisions, including the prohibition of vaccines [39] and the discouragement of using mind-altering substances [40], such as narcotics and sedatives. These findings may explain the high proportion of selftreatment among elders without the habit of drinking alcohol.

\section{Subgroups of elders with and without chronic diseases}

As mentioned above, the risk factors in the subgroup of elders with chronic diseases are similar to those of the whole subjects. However, no significant predictors were found in the model of the elders without chronic diseases, although the proportion of self-treatment was higher in this subgroup than its counterpart. Some of the studies found that the previous experience of the disease is one of the common reasons for self-medication [41, 42], and patients with chronic diseases are more likely equipped with experiential knowledge to self-treat. Nevertheless, the patients still favour assistance from a medical professional because of the limited perceived competence and worries about the potential adverse effects [43]. The regular appointment with medical professionals [32] and the high self-perceived risks may reduce the likelihood of self-treatment among elders with chronic diseases. Therefore, the association is reasonably stronger between the utilisation of family practice and the less likelihood to self-treat among elders with chronic diseases compared with the result of the model of the whole sample. As for the subgroups of the elders without chronic diseases, a possible explanation for the insignificant model is that the self-treatment for acute diseases is common across the population with low self-perceived health risks [44, 45]. Another explanation may relate to the bias from the low rates of the awareness of the presence of the chronic diseases among the rural elders in China, especially in rural areas [46].

\section{Subgroups of empty-nest and non-empty-nest elders}

Page 5/11 
The most innovative design of this study is the illustration of the risk factors of self-treatment among empty-nest elders and the comparison with non-emptynest elders. All independent predictors of self-treatment of empty-nest elders were in the category of health habits, including having the habits of self-care in TCM and no recent alcohol consumption. Therefore, health belief and habits may play important roles in the self-care practice of empty-nest elders because of the absence of younger family caregivers [49]. Due to the fewer side effects of TCM, the higher satisfaction with the doctors' communication skill [47, 48], and the expectation of removing the root of disease and health promotion, some of the Chinese people, especially the elderly, prefer to seek treatment in TCM sectors [22] or resort to some folk remedies [49] through word of mouths. Elders with the habits of self-care in TCM have higher affinities to TCM [28], and these elders tend to seek medical help in TCM sectors, in which they may be confronted with less barrier during the process of seeing doctors compared with the western medicine sectors [47, 48], especially for empty-nest elders without support from younger family caregivers [15]. This finding may explain the lower rate of self-treatment among elders with higher affinities for TCM in this empty-nest subgroup. Another possible explanation is that the people with the habits of self-care may have high perceived susceptibility and are likely to seek professional help instead of the risky self-treatment approaches. Some studies indicated that the self-care practice of some patients with chronic diseases is associated with the high perceived susceptibility of disorders [44, 45] . The association between self-treatment and the recent alcohol consumption is significant in the subgroup of non-empty-nest elders, which is insignificant in the model of its counterpart. The difference may be attributed to the absence of younger family caregivers who were thought to have an intervening effect on the elder individuals' health belief and medical decision-making in Chinese settings [49].

As for non-empty-nest elders, those who were no less than 75-year-old and in better health status reported higher rates of self-treatment. The older elders are in greater vulnerability of health and great need of care [50,51], and their family caregivers are often equipped with the knowledge of some common health problems and even some skills of healthcare tasks [52]. Given the long-term experience [32] of health problems and the inconvenience to visit doctors in remote areas [53], the older elders are likely to self-treat to cope with their discomforts with the support of their family caregiver when they are in a relatively stable health status.

\section{Implications for research and practice}

The findings of this study have important implications for the further development of the health service delivery system for the elderly in China, especially the primary care system in the rural areas.

First of all, the unequal prevalence of self-treatment in different population groups suggests the gaps existing between the elders' actual medical need and the health care delivery in local areas. The identification of the high risk population of self-treatment would deepen our understanding of the health-seeking patterns and the needs of some key populations, such as older elders with family caregivers, elders with chronic disease but in stable health condition and some minority ethnic groups with specific beliefs in health and medical care. Secondly, the strong association between the utilisation of family practice services and the lower rate of self-treatment implies the potential of family practice in improving the accessibility of the medical help for the rural elders. Currently the family practice system in China is still in its early stage [54,55]. A viable model of care [56] and more evidence-based practices are needed to improve the family practice system in China. The findings of this study may provide some clues to assist the redesign of the service and develop relevant improvement strategies of the family practice for the elders. For example, the result of the subgroup of non-empty-nest elders suggested the substantial need of health education for family caregivers of the older elders [57-58]. Thirdly, it shows that the affinity to TCM plays an important role in the rural elders' medical decision-making. Therefore, promoting TCM in primary care has great potential to improve the residents' acceptance and utilisation of primary care. TCM services have been integrated into primary care for over a decade in China, and more related development strategies need to be evaluated and implemented, such as the insurance coverage [59].

However, appropriate self-treatment can bring convenience for individuals and help save medical cost [60], which will also benefit the healthcare system [61]. In consideration of the advantages and risks of self-treatment, as well as a rising prevalence of long-term conditions, multiple medicines and increased health care utilisation, the roles of community pharmacists [62] and clinical pharmacists working within family practice have received increasing interest [63]. Compared with some western countries, the pharmacist system in China is still immature [64], including the clinical pharmacists in family practice, which should also be attached importance to in developing improvement strategies for primary care.

\section{Limitations}

Nevertheless, the study has several limitations. Firstly, the lack of standard definition for self-treatment makes the present results difficult to compare with previous findings $[7,13]$. Another limitation is the nature of the questionnaires. The questionnaires did not contain more details of the subjects' self-treatment behaviour. Self-reported information may also lead to some reporting bias or recall bias because the majority of the respondents are less educated elders who may have limited cognitive and communicative functioning [65]. In addition, the potential seasonal variation in health condition as well as in the health seeking pattern is unavoidable, especially for the elders, which may limit the generalisability of the study.

\section{Conclusion}

In general, stable health status, no recent alcohol consumption and no utilisation of family practice are associated with self-treatment among rural elders. In addition, advanced age and habits of self-care in TCM play roles in some subgroups. The findings suggest the potential of family practice in improving the care for rural elders. The identification of the determinants of some specific population groups may provide clues for the improvement strategies of healthcare delivery system for the rural elders, such as the health education for family caregivers and the development of TCM services in primary care. Further studies 
on self-treatment patterns and decision-making mechanisms are needed to elucidate the potential need and access barriers of healthcare among rural elders and thus improve the healthcare delivery system for the elderly in China and other LMICs with similar conditions.

\section{List Of Abbreviations}

TCM: traditional Chinese medicine; LMICs: low and middle income countries; CNHS: China National Health Survey; ADR: adverse drug reactions; TTO: time trade-off; OTC: over-the-counter

\section{Declarations}

\section{Ethics approval and consent to participate}

The study was approved by the ethics committee of Tongji Medical College, Huazhong University of Science and Technology (IORG No: IORG0003571). Inform consent was obtained from the participants enrolled in the household survey, and the residents were assured that their participation was voluntary and they could withdraw from the study at any time.

\section{Consent for publication}

Not applicable.

\section{Availability of data and materials}

The datasets used and analysed during the current study are available from the corresponding author on reasonable request.

\section{Competing interests}

The authors declare that they have no competing interests.

\section{Funding}

This work was funded by National Natural Science Foundation of China (Grant NO: 71734003). The funder had no role in study design, data collection and analysis, or manuscript preparation.

\section{Authors' contributions}

WCX, ZL and LZ drafted the outline of this study. All co-authors were responsible to collect the data. ZL performed the data management. WCX and ZJP performed the data analysis. All co-authors critically reviewed the first results. WCX drafted the first manuscript, and ZL, RBH, ZJP, LZ gave critical feedback. All authors read and approved the final manuscript.

\section{Acknowledgements}

We sincerely thank to all the government officers and residents involved in this study. This work wouldn't have been possible without their generous assistance. Besides, we thank all the investigators in the household survey.

\section{References}

1. Araujo DCl, Epping-Jordan J, Pot AM, Kelley E, Toro N, Thiyagarajan JA, Beard JR. Organizing integrated health-care services to meet older people's needs. Bull World Health Organ. 2017;95(11):756-763

2. Jacobs B, Ir P, Bigdeli M, Annear PL, Van Damme W. Addressing access barriers to health services: an analytical framework for selecting appropriate interventions in low-income Asian countries. Health Policy Plann.2012;27(4):288-300.

3. Duckett J, Hunt K, Munro N, Sutton M. Does distrust in providers affect health-care utilization in China? Health Policy Plann. 2016;31(8):1001-9.

4. Gilson L. Trust in health care: theoretical perspectives and research needs. J Health Organ Manag. 2006;20(5):359-75.

5. Holroyd E. Health-Seeking Behaviors and Social Change: The Experience of the Hong Kong Chinese Elderly. Qual Health Res. 2002;12(6):731-50.

6. An Analysis Report of the Fifth National Health Services Survey in China, 2013. Beijing: Peking Union Medical College Press; 2015.

7. Jerez-Roig J, Medeiros LFB, Silva VAB, Bezerra CLPA, Cavalcante LAR, Piuvezam G, Souza DLB. Prevalence of Self-Medication and Associated Factors in an Elderly Population: A Systematic Review. Drug Aging. 2014;31(12):883-96.

8. Jiang Y, Wang Y, Li Y, Wang X, Ma C, Ma S. Prevalence, characteristics, and cost of self-treatment in the middle-aged and elderly: observations from Henan, China. Public Health. 2015;129(5):597-600. 
9. Jain S, Malvi R, Purviya JK. Concept of Self Medication: A Review. International Journal of Pharmaceutical \& Biological Archives. 2011;2(3):831-36.

10. Meranius MS, Hammar LM. How does the healthcare system affect medication self-management among older adults with multimorbidity? Scand J Caring Sci. 2016;30(1):91-8.

11. Vali L, Pourreza A, Foroushani AR, Sari AA, Pharm DHH. An Investigation on Inappropriate Medication Applied among Elderly Patients. World Applied Sciences Journal. 2012;16(6):819-25.

12. Yuefeng L, Keqin R, Xiaowei R. Use of and factors associated with self-treatment in China. BMC Public Health. 2012;12(1):995.

13. Wang R, Ma C, Jiang K, Li M, Ma S. Descriptions of self-treatment for the middle-aged and elderly in Shanxi, China. Plos One. 2018;13(6):

14. The Role of the Pharmacist in Self-Care and Self-Medication. The Netherlands: WHO Press;1998.

15. Mortazavi SS, Shati M, Khankeh HR, Ahmadi F, Mehravaran S, Malakouti SK. Self-medication among the elderly in Iran: a content analysis study. BMC Geriatr. 2017;17(1):198.

16. Kuang L, Liang Y, Mei J, Zhao J, Wang Y, Liang H, Shi L. Family practice and the quality of primary care: a study of Chinese patients in Guangdong Province. Fam Pract. 2015;32(5):557-63.

17. Beach SR, Schulz R. Family Caregiver Factors Associated with Unmet Needs for Care of Older Adults. J Am Geriatr Soc. 2017;65(3):560-6.

18. Liu LJ, Guo Q. Life satisfaction in a sample of empty-nest elderly: a survey in the rural area of a mountainous county in China. Qual Life Res. 2008;17(6):823-30.

19. Wolff JL, Roter DL. Family presence in routine medical visits: A meta-analytical review. Soc Sci Med. 2011;72(6):823-31.

20. Lavretsky $\mathrm{H}$. The role of family caregivers and inappropriate medication use in the community-dwelling older adults with dementia. Aging Health. 2012;8(5):457-60.

21. Zhou C, Ji C, Chu J, Medina A, Li C, Jiang S, Zheng W, Liu J, Rozelle S. Non-use of health care service among empty-nest elderly in Shandong, China: a cross-sectional study. BMC Health Serv Res. 2015;115:294.

22. Chung VCH, Ma PHX, Lau CH, Wong SYS, Yeoh EK, Griffiths SM. Views on traditional Chinese medicine amongst Chinese population: a systematic review of qualitative and quantitative studies. Health Expect. 2014;17(5):622-36.

23. Zhong Z, Shen Z, Ding S, Zheng F, Duan Y, Luo A. Status for self-medication based on bibliometric study in China. J Cent South Univ. 2017;42(4):434-9.

24. Zhang X, Yu B, He T, Wang P. Status and determinants of health services utilization among elderly migrants in China. Glob Health Res Policy. 2018;3:8-17.

25. Buttorff C, Ruder T, Bauman M. Multiple Chronic Conditions in the United States. Santa Monica: RAND Corporation; 2017.

26. Lu C. Poverty and development in China: alternative approaches to poverty assessment. 1st ed. London: Routledge; 2011.

27. Liu GG, Wu H, Li M, Gao C, Luo N. Chinese Time Trade-Off Values for EQ-5D Health States. Value Health. 2014;17(5):597-604.

28. Chung VCH, Wong SYS, Wang HHX, Wong MCS, Wei X, Wang J, Liu S, Ho RST, Yu ELM, Griffiths SM. Use of Traditional and Complementary Medicine as Self-Care Strategies in Community Health Centers. Medicine. 2016;95(23):e3761.

29. China National Health C Implementation plan for the three-year program of poverty alleviation through medical aid. China National Health Commission. 2018. www.nhc.gov.cn/xxgk/pages/viewdocument.jsp?

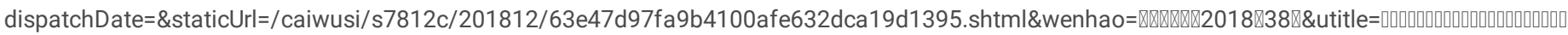
\&topictype=\&topic=\&publishedOrg=咽\&indexNum=000013610/2018-00318\&manuscriptld=63e47d97fa9b4100afe632dca19d1395. Accessed 7 Apr 2019.

30. O'Donnell O. Access to health care in developing countries: breaking down demand side barriers. Cadernos de saude publica, 2007;23:2820-34.

31. Chang J, Wang Q, Fang Y. Socioeconomic differences in self-medication among middle-aged and older people: data from the China health and retirement longitudinal study. BMJ Open. 2017;7(12):e17306.

32. Niclos G, Olivar T, Rodilla V. Factors associated with self-medication in Spain: a cross-sectional study in different age groups. Int J Pharm Pract. 2018;26(3):258-66.

33. Shafaeei Y, Sharifirad G, Kamran A, Mohebi S. Associations between self-medication, health literacy, and self-perceived health status: A community-based study. Int J Prev Med. 2015;6:66.

34. Li J, Shi L, Liang H, Ding G, Xu L. Urban-rural disparities in health care utilization among Chinese adults from 1993 to 2011. BMC Health Serv Res. 2018;18(1):102.

35. Aira M, Hartikainen S, Sulkava R. Drinking alcohol for medicinal purposes by people aged over 75: a community-based interview study. Fam Pract 2008;25(6):445-9.

36. Li HZ, Rosenblood L. Exploring factors influencing alcohol consumption patterns among Chinese and Caucasians. Journal of Studies on Alcohol. 1994;55(4):427-33.

37. Al-Ansari B, Thow A, Day CA, Conigrave KM. Extent of alcohol prohibition in civil policy in Muslim majority countries: the impact of globalization. Addiction. 2016;111(10):1703-13.

38. Padela Al, Curlin FA. Religion and Disparities: Considering the Influences of Islam on the Health of American Muslims. Journal of Religion and Health. 2013;52(4):1333-45.

39. Padela Al: Public health measures \& individualized decision-making: The confluence of the H1N1 vaccine and Islamic bioethics. Human vaccines 2010, $6(9)$.

40. Davidson JE, Boyer ML, Casey D, Matzel SC, Walden CD. Gap analysis of cultural and religious needs of hospitalized patients. Critical Care Nursing Quarterly. 2008;31(2):119-26. 
41. 41. Wen Y, Lieber E, Wan D, Hong Y. A qualitative study about self-medication in the community among market vendors in Fuzhou, China. Health Soc Care Community. 2011;19(5):504-513.

42. Lei X, Jiang H, Liu C, Ferrier A, Mugavin J: Self-Medication Practice and Associated Factors among Residents in Wuhan, China. INT J ENV RES PUB HE $2018,15: 681$.

43. Laue J, Melbye H, Risør MB. Self-treatment of acute exacerbations of chronic obstructive pulmonary disease requires more than symptom recognition - a qualitative study of COPD patients'perspectives on self-treatment. BMC Fam Pract. 2017;18:8.

44. Dehghani-Tafti A, Mazloomy Mahmoodabad SS, Morowatisharifabad MA, Afkhami Ardakani M, Rezaeipandari H, Lotfi MH. Determinants of Self-Care in Diabetic Patients Based on Health Belief Model. Glob J Health Sci. 2015;7(5):33-42.

45. Larki A, Tahmasebi R, Reisi M. Factors Predicting Self-Care Behaviors among Low Health Literacy Hypertensive Patients Based on Health Belief Model in Bushehr District, South of Iran. Int J Hypertens. 2018:9752736.

46. WHO: China country assessment report on ageing and health. Geneva: WHO Press; 2015.

47. Zhang JJ, Verhoef MJ. Illness management strategies among Chinese immigrants living with arthritis. Soc Sci Med. 2002;55(10):1795-802.

48. Green G, Bradby H, Chan A, Lee M. "We are not completely Westernised": Dual medical systems and pathways to health care among Chinese migrant women in England. Soc Sci Med. 2006;62(6):1498-509.

49. Dixon B. Cultural Traditions and Healthcare Beliefs of Some Older Adults. Winnipeg: Red River College; 2009.

50. Kuluski K, Gill A, Naganathan G, Upshur R, Jaakkimainen RL, Wodchis WP. A qualitative descriptive study on the alignment of care goals between older persons with multi-morbidities, their family physicians and informal caregivers. BMC Fam Pract. 2013;14:133.

51. Little W, Vyain S, Scaramuzzo G, Cody-Rydzewski S, Griffiths H, Strayer E, Keirns N, McGivern R. Aging and the Elderly. In Little W, McGivern R, editors. Introduction to Sociology-1st Canadian Edition. Victoria: BCcampus; 2014.

52. Bassah N, Ubenoh US, Palle JN. An Exploratory Study of the Knowledge and Practices of Family Caregivers in the Care of the Elderly at Home in the Buea Health District, Cameroon. J Gerontol Geriatr Res. 2018;7(3):473.

53. Ibrahim MIM, Wertheimer Al. Sociobehavioral Aspects of Medicines Use in Developing Countries. In Ibrahim MIM, Wertheimer Al, Babar Z, editors. Social and Administrative Aspects of Pharmacy in Low- and Middle-Income Countries. London: Academic Press; 2018. p. 15-26.

54. Pan G, Yang Y. The Current Situation of Family Doctor Team Services Mode. Chinese General Practice. 2017;20(28):3457-62.

55. Liu S, Yu C, Chen L, Li Q, Wu Z, Li M, Liu Z. Assessment of service quality of family doctor service modelin rural areas based on SERVQUAL. Anhui Medical Journal. 2017;38(1):93-6.

56. Bhattacharyya O, Delu Y, Wong ST, Bowen C. Evolution of primary care in China 1997- Health Policy. 2011;100(2-3):174-80.

57. Reinhard SC, Given B, Petlick NH, Bemis A. Supporting Family Caregivers in Providing Care. In Hughes R editor. Patient Safety and Quality: An EvidenceBased Handbook for Nurses. Rockville: Agency for Healthcare Research and Quality (US); 2008. p. 347-410.

58. Lau DT, Kasper JD, Hauser JM, Berdes C, Chang C, Berman RL, Masin-Peters J, Paice J, Emanuel L. Family Caregiver Skills in Medication Management for Hospice Patients: A Qualitative Study to Define a Construct. J Gerontol B-Psychol. 2009;64(6):799-807.

59. Chung VCH, Ma PHX, Wang HHX, Wang JJ, Hong LC, Wei X, Wong SYS, Tang JL, Griffiths SM. Integrating Traditional Chinese Medicine Services in Community Health Centers: Insights into Utilization Patterns in the Pearl River Region of China. Evid-Based Compl Alt. 2013;2013:

60. Noone J, Blanchette CM. The value of self-medication: summary of existing evidence. J Med Econ. 2018;21(2):201-11.

61. Hughes C, C. McElnay J, Fleming G. Benefits and Risks of Self Medication. Drug Safety. 2001;24(14):1027-37.

62. You JH, Wong FY, Chan FW, Wong EL, Yeoh E. Public perception on the role of community pharmacists in self-medication and self-care in Hong Kong. BMC Clin Pharmacol. 2011, 11(1):19.

63. Cardwell K, Smith SM. Clinical pharmacists working within family practice: what is the evidence? Fam Pract. 2018;35(2):120-1.

64. Fang Y, Yang S, Zhou S, Jiang M, Liu J. Community pharmacy practice in China: past, present and future. Int J Clin Pharm. 2013;35(4):520-528

65. Knauper B, Carriere K, Chamandy M, Xu Z, Schwarz N, Rosen NO. How aging affects self-reports. Eur J Ageing. 2016;13(2):185-93.

\section{Tables}


Table 1 Rates of self-treatment and bivariate analysis of study variables

\begin{tabular}{|c|c|c|c|c|c|c|c|c|c|c|c|c|c|c|c|c|c|c|c|}
\hline \multirow{2}{*}{\multicolumn{2}{|c|}{ variables }} & \multicolumn{4}{|c|}{ Total } & \multicolumn{4}{|c|}{ non-NCD population } & \multicolumn{4}{|c|}{ NCD population } & \multicolumn{4}{|c|}{ non-empty nest } & \multicolumn{2}{|r|}{ empts } \\
\hline & & $\mathrm{N}$ & $\mathrm{n}$ & $\%$ & $\mathrm{P}$ & $\mathrm{N}$ & $\mathrm{n}$ & $\%$ & $\mathrm{p}$ & $\mathrm{N}$ & $\mathrm{n}$ & $\%$ & $\mathrm{p}$ & $\mathrm{N}$ & $\mathrm{n}$ & $\%$ & $\mathrm{p}$ & $\mathrm{N}$ & $\mathrm{n}$ \\
\hline \multicolumn{20}{|c|}{ socio-demographic status } \\
\hline \multirow[t]{2}{*}{ gender } & men & 160 & 48 & 30.0 & 0.029 & 38 & 15 & 39.5 & 0.326 & 122 & 33 & 27.1 & 0.064 & 80 & 24 & 30.0 & 0.087 & 80 & 24 \\
\hline & women & 176 & 73 & 41.5 & & 50 & 25 & 50.0 & & 126 & 48 & 38.1 & & 99 & 42 & 42.4 & & 77 & 31 \\
\hline \multirow[t]{2}{*}{ age } & $60-74$ & 284 & 97 & 34.2 & 0.097 & 71 & 31 & 43.7 & 0.490 & 213 & 66 & 31.0 & 0.165 & 144 & 46 & 31.9 & 0.006 & 140 & 51 \\
\hline & $\geq 75$ & 52 & 24 & 46.2 & & 17 & 9 & 52.9 & & 35 & 15 & 42.9 & & 35 & 20 & 57.1 & & 17 & 4 \\
\hline \multirow[t]{2}{*}{ poverty } & yes & 103 & 28 & 27.2 & 0.028 & 23 & 9 & 39.1 & 0.478 & 80 & 19 & 23.8 & 0.045 & 53 & 15 & 28.3 & 0.138 & 50 & 13 \\
\hline & no & 232 & 92 & 39.7 & & 65 & 31 & 47.7 & & 167 & 61 & 36.5 & & 125 & 50 & 40.0 & & 107 & 42 \\
\hline \multirow[t]{2}{*}{ empty-nest } & yes & 157 & 55 & 35.0 & 0.726 & 45 & 22 & 48.9 & 0.508 & 112 & 33 & 29.5 & 0.330 & - & & - & - & - & \\
\hline & no & 179 & 66 & 36.9 & & 43 & 18 & 41.9 & & 136 & 48 & 35.3 & & - & & - & - & - & \\
\hline \multirow[t]{2}{*}{ illiteracy } & yes & 144 & 55 & 38.2 & 0.470 & 36 & 16 & 44.4 & 0.874 & 108 & 39 & 36.1 & 0.309 & 81 & 35 & 43.2 & 0.110 & 63 & 20 \\
\hline & no & 192 & 66 & 34.4 & & 52 & 24 & 46.2 & & 140 & 42 & 30.0 & & 98 & 31 & 31.6 & & 94 & 35 \\
\hline \multicolumn{20}{|c|}{ health status } \\
\hline \multirow[t]{2}{*}{$\begin{array}{l}\text { chronic } \\
\text { diseases }\end{array}$} & yes & 248 & 81 & 32.7 & 0.032 & - & - & - & - & - & - & - & - & 136 & 48 & 35.3 & 0.437 & 112 & 33 \\
\hline & no & 88 & 40 & 45.5 & & - & - & - & - & - & - & - & - & 43 & 18 & 41.9 & & 45 & 22 \\
\hline \multirow{2}{*}{$\begin{array}{l}\text { multi- } \\
\text { morbidities }\end{array}$} & yes & 77 & 19 & 24.7 & 0.018 & - & - & - & - & 77 & 19 & 24.7 & 0.072 & 47 & 13 & 27.7 & 0.127 & 30 & 6 \\
\hline & no & 259 & 102 & 39.4 & & - & - & - & - & 171 & 62 & 36.3 & & 132 & 53 & 40.2 & & 127 & 49 \\
\hline \multicolumn{20}{|c|}{ health behaviors } \\
\hline \multirow[t]{2}{*}{$\begin{array}{l}\text { self-care in } \\
\text { TCM }\end{array}$} & yes & 216 & 70 & 32.4 & 0.065 & 47 & 22 & 46.8 & 0.785 & 169 & 48 & 28.4 & 0.036 & 113 & 40 & 35.4 & 0.593 & 103 & 30 \\
\hline & no & 120 & 51 & 42.5 & & 41 & 18 & 43.9 & & 79 & 33 & 41.8 & & 66 & 26 & 39.4 & & 54 & 25 \\
\hline \multirow{2}{*}{$\begin{array}{l}\text { drinking } \\
\text { alcohol }\end{array}$} & yes & 71 & 14 & 19.7 & 0.002 & 16 & 4 & 25.0 & 0.087 & 55 & 10 & 18.2 & 0.011 & 36 & 8 & 22.2 & 0.046 & 35 & 6 \\
\hline & no & 262 & 104 & 39.7 & & 70 & 34 & 48.6 & & 192 & 70 & 36.5 & & 142 & 57 & 40.1 & & 120 & 47 \\
\hline \multicolumn{20}{|c|}{ health service } \\
\hline \multirow[t]{3}{*}{ distance $^{\mathrm{a}}$} & $<1 \mathrm{~km}$ & 191 & 70 & 36.7 & 0.800 & 49 & 20 & 40.8 & 0.558 & 142 & 50 & 35.2 & 0.426 & 105 & 40 & 38.1 & 0.910 & 86 & 30 \\
\hline & $\begin{array}{c}2- \\
3 \mathrm{~km}\end{array}$ & 104 & 35 & 33.7 & & 26 & 14 & 53.9 & & 78 & 21 & 26.9 & & 59 & 21 & 35.6 & & 45 & 14 \\
\hline & $>3 \mathrm{~km}$ & 41 & 16 & 39.0 & & 13 & 6 & 46.2 & & 28 & 10 & 35.7 & & 15 & 5 & 33.3 & & 26 & 11 \\
\hline \multirow{2}{*}{$\begin{array}{l}\text { family } \\
\text { practice }^{b}\end{array}$} & yes & 161 & 49 & 30.4 & 0.037 & 38 & 16 & 42.1 & 0.582 & 123 & 33 & 26.8 & 0.047 & 98 & 32 & 32.7 & 0.198 & 63 & 17 \\
\hline & no & 174 & 72 & 41.4 & & 50 & 24 & 48.0 & & 124 & 48 & 38.7 & & 81 & 34 & 42.0 & & 93 & 38 \\
\hline
\end{tabular}

\footnotetext{
${ }^{a}$ distance to the nearest medical institution

${ }^{b}$ utilization of family practice service
} 
Table 2 Logistic regression analysis for study variables on self-treatment among the subjects

\begin{tabular}{|c|c|c|c|c|c|c|}
\hline \multicolumn{2}{|l|}{ variables } & $\begin{array}{l}\text { Total } \\
\text { OR }(95 \% \mathrm{CI})\end{array}$ & $\begin{array}{l}\text { non-NCD group } \\
\text { OR }(95 \% \mathrm{CI})\end{array}$ & $\begin{array}{l}\text { NCD group } \\
\text { OR (95\%CI) }\end{array}$ & $\begin{array}{l}\text { non-empty nest } \\
\text { OR }(95 \% \mathrm{CI})\end{array}$ & $\begin{array}{l}\text { empty nest } \\
\text { OR (95\%CI) }\end{array}$ \\
\hline \multicolumn{7}{|c|}{ socio-economic status } \\
\hline \multirow[t]{2}{*}{ gender } & men & 1 & 1 & 1 & 1 & 1 \\
\hline & women & 1.68 (0.95 to 2.97$)$ & $1.72(0.50$ to 5.91$)$ & 1.76 (0.90 to 3.43$)$ & $1.52(0.68$ to 3.39$)$ & $1.98(0.84$ to 4.64$)$ \\
\hline \multirow[t]{2}{*}{ age } & $60-75$ & 1 & 1 & 1 & 1 & 1 \\
\hline & $\geq 75$ & 1.71 (0.87 to 3.35$)$ & 1.31 (0.38 to 4.52$)$ & 2.03 (0.88 to 4.68$)$ & $3.10(1.32 \text { to } 7.20)^{* *}$ & $0.43(0.11$ to 1.68$)$ \\
\hline \multirow[t]{2}{*}{ poverty } & no & 1 & 1 & 1 & 1 & 1 \\
\hline & yes & 0.69 (0.40 to 1.18$)$ & 0.76 (0.24 to 2.40$)$ & 0.64 (0.33 to 1.22$)$ & 0.76 (0.35 to 1.63$)$ & $1.98(0.84$ to 4.64$)$ \\
\hline \multirow[t]{2}{*}{ empty-nest } & no & 1 & 1 & 1 & - & - \\
\hline & yes & 0.94 (0.57 to 1.55$)$ & 1.52 (0.56 to 4.12$)$ & 0.70 (0.38 to 1.29$)$ & - & - \\
\hline \multirow[t]{2}{*}{ illiteracy } & no & 1 & 1 & 1 & 1 & 1 \\
\hline & yes & $0.88(0.51$ to 1.53$)$ & 0.66 (0.20 to 2.16$)$ & 0.95 (0.50 to 1.83$)$ & 1.15 (0.53 to 2.47$)$ & $0.54(0.22$ to 1.33$)$ \\
\hline \multicolumn{7}{|l|}{ health status } \\
\hline \multirow[t]{2}{*}{$\begin{array}{l}\text { chronic } \\
\text { diseases }\end{array}$} & no & 1 & - & - & 1 & 1 \\
\hline & yes & 0.87 (0.50 to 1.52$)$ & - & - & 1.37 (0.60 to 3.15$)$ & $0.54(0.24$ to 1.23$)$ \\
\hline \multicolumn{2}{|l|}{ TTO-value } & $\begin{array}{l}6.75(1.93 \text { to } \\
23.60)^{* *}\end{array}$ & $\begin{array}{l}1.07(0.10 \text { to } \\
11.44)\end{array}$ & $\begin{array}{l}13.56(2.81 \text { to } \\
65.39) * *\end{array}$ & $\begin{array}{l}9.20(1.73 \text { to } \\
48.75)^{* *}\end{array}$ & $\begin{array}{l}4.50(0.61 \text { to } \\
33.04)\end{array}$ \\
\hline \multicolumn{7}{|l|}{ health behaviors } \\
\hline \multirow{2}{*}{$\begin{array}{l}\text { self-care in } \\
\text { TCM }\end{array}$} & no & 1 & 1 & 1 & 1 & 1 \\
\hline & yes & $0.70(0.42$ to 1.16$)$ & 1.03 (0.38 to 2.82$)$ & 0.59 (0.32 to 1.09$)$ & 0.89 (0.42 to 1.86$)$ & $\begin{array}{l}0.39(0.18 \text { to } \\
0.86)^{*}\end{array}$ \\
\hline \multirow{2}{*}{$\begin{array}{l}\text { drinking } \\
\text { alcohol }\end{array}$} & no & 1 & 1 & 1 & 1 & 1 \\
\hline & yes & $0.42 \llbracket 0.21$ to $0.83 \llbracket *$ & 0.36 (0.09 to 1.56$)$ & $0.41(0.18 \text { to } 0.91)^{*}$ & 0.48 (0.19 to 1.22$)$ & $\begin{array}{l}0.28(0.10 \text { to } \\
0.82)^{*}\end{array}$ \\
\hline \multicolumn{7}{|l|}{ health service } \\
\hline \multirow[t]{3}{*}{ distance $^{\mathrm{a}}$} & $<1 \mathrm{~km}$ & 1 & 1 & 1 & 1 & 1 \\
\hline & $2-3 \mathrm{~km}$ & 0.78 (0.45 to 1.35$)$ & 1.51 (0.54 to 4.22$)$ & 0.55 (0.27 to 1.10$)$ & 0.87 (0.42 to 1.80$)$ & 0.87 (0.34 to 2.16$)$ \\
\hline & $>3 \mathrm{~km}$ & 0.84 (0.39 to 1.86 & $0.60(0.11$ to 3.19$)$ & $0.83(0.33$ to 2.10$)$ & $0.72(0.20$ to 2.63$)$ & $1.00(0.35$ to 2.92$)$ \\
\hline \multirow{2}{*}{$\begin{array}{l}\text { family practice } \\
\text { b }\end{array}$} & no & 1 & 1 & 1 & 1 & 1 \\
\hline & yes & $0.59(0.36 \text { to } 0.96)^{*}$ & 0.85 (0.33 to 2.17$)$ & $0.49(0.27 \text { to } 0.89)^{* *}$ & 0.65 (0.33 to 1.26$)$ & $0.53(0.24$ to 1.16$)$ \\
\hline
\end{tabular}

\footnotetext{
* $\mathrm{P}<0.05 ; * * \mathrm{P}<0.01$

${ }^{a}$ distance to the nearest medical institution

$\mathrm{b}$ utilization of family practice service
} 